\title{
Hand anthropometry in patients with carpal tunnel syndrome: a case-control study with a matched control group of healthy volunteers
}

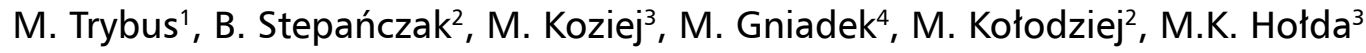 \\ ${ }^{1} 2^{\text {nd }}$ Department of General Surgery, Jagiellonian University Medical College, Krakow, Poland \\ 2Department of Anthropology, Jagiellonian University, Krakow, Poland \\ ${ }^{3}$ Department of Anatomy, Jagiellonian University, Krakow, Poland \\ ${ }^{4}$ University Hospital, Jagiellonian University Medical College, Krakow, Poland \\ [Received: 18 March 2018; Accepted: 30 April 2018]
}

Background: The aim of this study was to perform anthropometrical measurements of patients' hands with carpal tunnel syndrome (CTS) in order to evaluate if there is a correlation between CTS occurrence and hand features regarding sexual dimorphism, age and physical activity.

Materials and methods: Study sample consisted of 48 patients (33 females) and control group included 80 healthy volunteers (58 females) with no history of CTS. The following measurements were performed: the wrist circumference, length of the hand, the hand's width, width of the wrist, thickness of the wrist, height of the hypothenar and thenar, length of the arm and forearm, circumference of the proximal phalanges and width of the digits; as well as several indexes were calculated i.e.: body mass index (BMI), shape index, digit index, wrist index, hand length/height ratio (HLH-ratio) and hand length/upper limb length ratio (HLULL-ratio).

Results: Correlation coincidences were analysed between circumferences within the hand, palm and body weight. All parameters except fingers were correlated with body weight in either gender in both groups ( $<<0.05 ; r=0.40-0.80$ ); Furthermore, width of the hand was correlated with body height $(p<0.001$; $r=0.56-0.71)$. Mean values of wrist index for CTS patients were: males: 0.8, females: 0.74 (significantly higher than in healthy individuals and indicating square shape); shape index: males 76.5, females 75.8; digit index: males 55.7, females 56.5. The calculated HLH-ratio in CTS group was: males 10.6, females 10.9; HLULL-ratio: males 23.6, females 24.9 and they did not differ significantly from healthy volunteers. Almost $90.0 \%$ of females with diagnosed CTS have BMI $>25.0 \mathrm{~kg} / \mathrm{m}^{2}$.

Conclusions: There are significant differences in morphometrical features of the upper limbs between CTS patients and healthy individuals. Hands of patients with CTS are more massive and with 'plumb' fingers and square shape of the wrist. Furthermore, higher BMI values were confirmed to be predisposing factors in CTS occurrence. (Folia Morphol 2019; 78, 1: 182-190)

Key words: carpal tunnel syndrome, anthropometry, risk factor, shape index, wrist, hand measurements 


\section{INTRODUCTION}

The carpal tunnel syndrome (CTS) is the most common neuropathy of the upper limb, affecting approximately $3.8 \%$ of general population, and affects women three times as often as men. The highest incidence is noted between $4^{\text {th }}$ and $6^{\text {th }}$ decade of life, but it can manifest in every age group [1, 3]. The CTS is caused by an increased pressure within the carpal tunnel, which leads to clinical symptoms, followed by damage to the median nerve [4]. The most common treatment is to release the transverse carpal ligament in the carpal tunnel [3].

Several previous studies list many risk factors for CTS, including diabetes, hypothyroidism, middle age, female gender and physique $[2,27,32,34]$. Moreover, other authors have shown that anatomical features, such as a size of a hand and wrist are correlated with CTS occurrence $[5,30,35]$. During the examination of patients with CTS, we have observed some anatomical differences in hands affected by the disease. Primarily, they were more massive, broader and included a deeper wrist. Our team decided to design a case-control study with a matched control group. Anthropometrical measurements of patients' hands with CTS were obtained in order to assess if there are correlations between CTS occurrence and hand features regarding sexual dimorphism, age and physical activity.

\section{MATERIALS AND METHODS}

This study was approved by the Bioethical Committee of the Jagiellonian University, Krakow, Poland (KBET/240/B/2013). All necessary consents, written as well as oral, was taken from patients and volunteers before examination. The study protocol conforms to the ethical guidelines of the 1975 Declaration of Helsinki.

\section{Study group}

The study sample consisted of 48 consecutive CTS patients ( 33 females, $68.8 \%$ ) admitted to $2^{\text {nd }}$ Department of Surgery, Jagiellonian University Medical College in Krakow, Poland, between June and December 2014. The exclusion criteria were: diabetes, hypothyroidism and rheumatoid arthritis. Patients included in the study had a history of CTS confirmed by examination, electromyography/nerve velocity and ultrasonography. A total of 25 patients (52\% of all cases) had CTS unilaterally; 14 right ( 10 females) and 11 left ( 5 females). Both hands were examined in the remaining $23(48 \%)$ patients (18 females), where CTS occurred bilaterally. Patients were mainly right side dominant, except for 1 ambidextrous person. In total, 71 hands were anthropometrically measured, 37 right and 34 left.

\section{Control group}

The control group consisted of 80 healthy volunteers (58 females, $72.5 \%$ ) with no history of CTS and other hand diseases or trauma. Only persons above 30 years old were included in the study to make the study and control groups similar. Three volunteers were ambidextrous. The dominant hands of the volunteers were examined, right hand if ambidextrous. In total, 80 hands were examined, 78 right and 2 left.

\section{Anthropometric measurements}

The measurements obtained in the study are presented in Table 1 and Figure 1 and were performed using: electronic weighing scale with height meter (WPT 60/150 OW, Radwag, Poland) accurate to $0.1 \mathrm{~cm}$ and $0.1 \mathrm{~kg}$, measuring tape $(0.1 \mathrm{~cm}$ accuracy $)$ and electronic calliper (YT-7201, YATO, Poland) with $0.1 \mathrm{~cm}$ precision. During measurement the patients were sitting with the elbow joint in $90^{\circ}$ flexion.

Based on the measured values, the following parameters were calculated:

- shape index (hand width in the metacarpus [mm] $\times 100 /$ hand length $[\mathrm{mm}]$ );

- digit index (digit length $[\mathrm{mm}] \times 100 /$ hand length $[\mathrm{mm}]$ );

- wrist index (wrist depth [mm] / wrist width [mm]);

- hand length $[\mathrm{cm}] /$ height $[\mathrm{m}]$ ratio;

- hand length $[\mathrm{cm}] /$ upper limb length $[\mathrm{cm}]$ ratio;

- body mass index (BMI), which was calculated as weight divided by height squared $\left[\mathrm{kg} / \mathrm{m}^{2}\right]$.

\section{Statistical analysis}

Data are presented as mean values, corresponding standard deviations and percentages. The Student t-test and the Mann-Whitney U-test were executed for the statistical comparison between groups and genders. Correlation coefficients were calculated to measure statistical dependence and association between variables was tested using $\chi^{2}$ test. We performed statistical analyses with STATISTICA v.13.1 (StatSoft Inc., Tulsa, OK, USA). P-values less than 0.05 were considered statistically significant.

\section{RESULTS}

Table 2 shows demographic data of both study and control group. The mean age of the CTS patients was 
Table 1. Methods of measuring hand dimensions and body height

\begin{tabular}{|c|c|c|c|}
\hline \multirow{2}{*}{$\begin{array}{l}\text { Measurement } \\
\begin{array}{l}\text { Measurements } \\
\text { of the fingers }\end{array}\end{array}$} & \multirow[b]{2}{*}{ L1-L5 } & \multirow[b]{2}{*}{ Digits length I-V } & \multirow{2}{*}{$\begin{array}{l}\text { Methods } \\
\text { The total length of the fingers } I-V \text { measured on the dorsal side of the point } \\
\text { phalangion to the tip of the fingers }\end{array}$} \\
\hline & & & \\
\hline & W1-W5 & Width of the proximal phalanges $\mathrm{I}-\mathrm{V}$ & $\begin{array}{l}\text { Width of the proximal phalanges } \mathrm{I}-\mathrm{V} \text { is made analogous to the measurement } \\
\text { of phalanges distal — at the site of the joint between the elements and } \\
\text { second fingers }\end{array}$ \\
\hline & F1-F5 & Functional length of the digits $\mathrm{I}-\mathrm{V}$ & $\begin{array}{l}\text { Functional finger length } \mathrm{I}-\mathrm{V} \text { measured on the inside of the hand groove base } \\
\text { of the fingers to the top }\end{array}$ \\
\hline & C1-C5 & Circumference of the proximal phalanges $\mathrm{I}-\mathrm{V}$ & Circumference of the central part of the proximal phalanges \\
\hline \multirow[t]{9}{*}{$\begin{array}{l}\text { Measurements } \\
\text { of the hand }\end{array}$} & L6 & Palm length without fingers & $\begin{array}{l}\text { The length of the hand without fingers was measured on the inner side of the } \\
\text { point stylion - the lowest positioned styloid process, the finger groove III }\end{array}$ \\
\hline & L7 & Hand length & $\begin{array}{l}\text { The measurement was made on the dorsal side of the point stylion to the } \\
\text { tops of finger III }\end{array}$ \\
\hline & W6 & Hand width in the metacarpus & $\begin{array}{l}\text { Hand width in the metacarpus were measured at the dorsal side of a hand } \\
\text { with the dissuaded thumb, measurement made between points metacarpale } \\
\text { radials - point from the radial bone and metacarpale ulnare - a point on } \\
\text { the palm side of the ulna }\end{array}$ \\
\hline & $\mathrm{H} 1$ & Palm thickness & $\begin{array}{l}\text { The thickness of the palm [hand plane sbc-II] was measured by setting one } \\
\text { arm compass parallel to the plane of the palm upright, with joined fingers II-V } \\
\text { and dissuaded thumb, and the largest point on the basis of the second } \\
\text { metacarpal bone }\end{array}$ \\
\hline & $\mathrm{H} 2$ & Height of hypothenar & $\begin{array}{l}\text { Height was measured from the side surface of the hand between the dorsal } \\
\text { and palmar side of the little finger }\end{array}$ \\
\hline & H3 & Height of thenar & $\begin{array}{l}\text { Height was measured from the medial side surface between the palmar } \\
\text { and dorsal side of the thumb }\end{array}$ \\
\hline & C6 & Circumference through fingers & $\begin{array}{l}\text { Circumference was measured at the joined fingers } \|-V \text {, slightly diagonally } \\
\text { by points within the joint of the proximal interphalangeal finger } \| \text { and } V\end{array}$ \\
\hline & $\mathrm{C} 7$ & Palm circumference & $\begin{array}{l}\text { Palm circumference measured guiding the tape through the points } \mathrm{mr}-\mathrm{mu} \text {, } \\
\text { somewhat oblique, keeping in mind the position of the thumb dissuaded }\end{array}$ \\
\hline & C8 & Hand circumference & Hand circumference measured by a tape metacarpophalangeal joint \\
\hline \multirow[t]{3}{*}{$\begin{array}{l}\text { Measurements } \\
\text { of the wrist }\end{array}$} & C9 & Circumference & $\begin{array}{l}\text { The circumference of the wrist measured in waist between distal base } \\
\text { forearm and metacarpus }\end{array}$ \\
\hline & W7 & Width & $\begin{array}{l}\text { The width of the wrist measured from the point of stylion on the ulna to } \\
\text { a point on the radius stylion }\end{array}$ \\
\hline & $\mathrm{H} 4$ & Depth & $\begin{array}{l}\text { The depth was measured at the centre between the dorsal and the inner } \\
\text { surface of the wrist }\end{array}$ \\
\hline \multirow{5}{*}{$\begin{array}{l}\text { Measurements } \\
\text { of body height }\end{array}$} & & Basion - vertex & From the floor (Basion) to the highest point on the head (vertex) \\
\hline & & Basion-acromion & $\begin{array}{l}\text { From the floor (Basion) to the most laterally situated point on the upper } \\
\text { edge of the acromion (acromion). }\end{array}$ \\
\hline & & Basion - dactylion & From the floor (Basion) to a point on the distal fingertip III (dactylion) \\
\hline & & Basion - stylion & $\begin{array}{l}\text { From the floor (Basion) to a point on the top of the styloid process of the } \\
\text { radius (stylion) }\end{array}$ \\
\hline & & Basion - radialis & $\begin{array}{l}\text { From the floor (Basion) to a point at the top circumference of the joint } \\
\text { radial head (radials) - at the height of the elbow joint }\end{array}$ \\
\hline
\end{tabular}

$60.7 \pm 11.5$ years (range: $36-81$ years). The mean age for the control group was $51.4 \pm 10.3$ years (range: 31-68 years). The patients in the control group were significantly younger in both sexes $(p<0.05)$. None of the measured hand parameters were correlated with age in a particular group or in either gender ( $p>0.05)$.

Participants' places of residence (urban vs. rural) and physical activity did not statistically determine any CTS occurrence in either gender $(p>0.05)$. A total of $66.7 \%$ of all patients with CTS and $70 \%$ of healthy volunteers were found to be physically active.

There was no significant difference in the length of digits I-V between groups and genders ( $p>0.05$ ). The same results were obtained in the functional length of digits $\mathrm{I}-\mathrm{V}(\mathrm{p}>\mathrm{0.05})$. Statistical comparison revealed differences in the width of proximal phalan- 


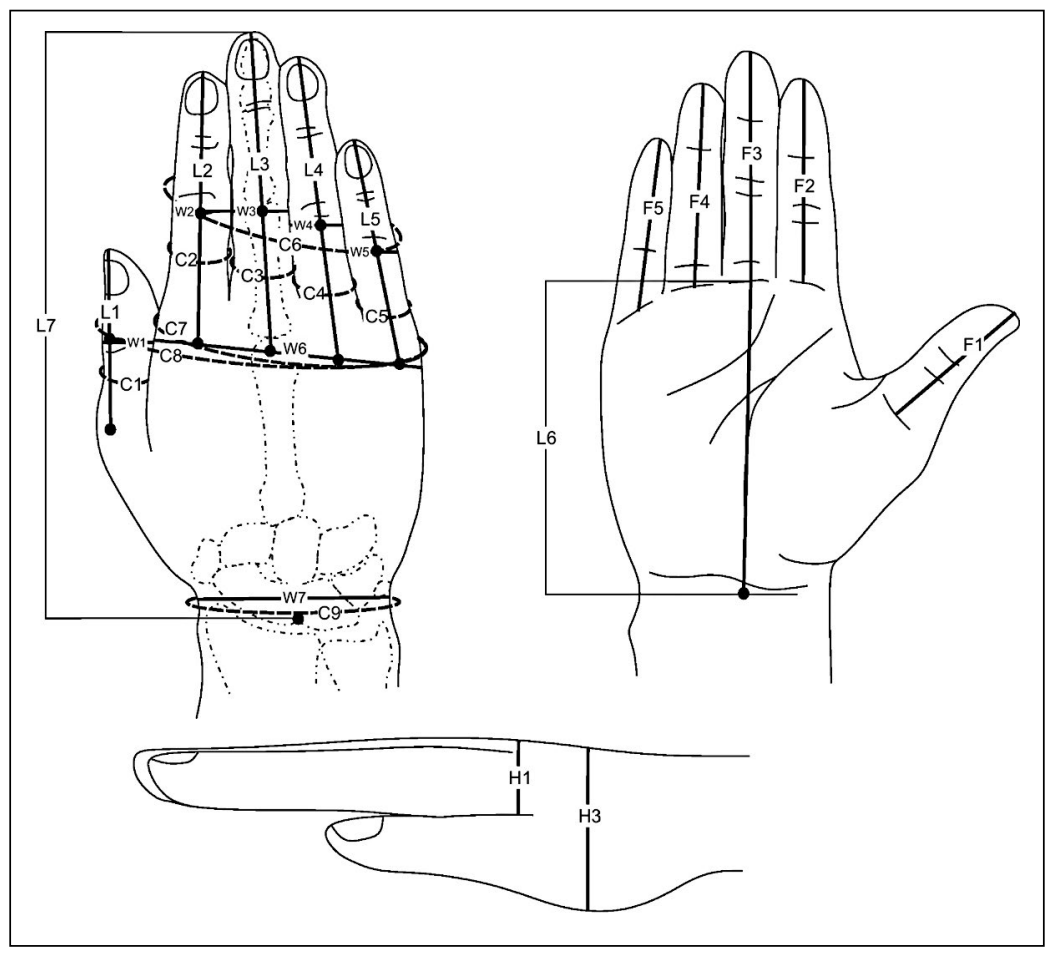

Figure 1. Anthropometric measurements performed in this study; L1-L5 — length of the digits; W1-W5 — width of the digits; F1-F5 - functional length of digits; C1-C5 - circumference of the proximal phalanges; L6 - length without fingers; L7 — hand length; W6 - hand width in the metacarpus; $\mathrm{H} 1$ - palm thickness; $\mathrm{H} 2$ - height of hypothenar; $\mathrm{H} 3$ - height of thenar; $\mathrm{C} 6$ - circumference through fingers; $\mathrm{C} 7$ palm circumference; $\mathrm{C} 8$ - hand circumference; $\mathrm{C} 9$ — wrist circumference; W7 — wrist width; $\mathrm{H} 4$ — wrist thickness.

Table 2. Demographic data of analysed groups

\begin{tabular}{|c|c|c|c|c|c|c|c|c|}
\hline & \multicolumn{4}{|c|}{ Males $(n=37)$} & \multicolumn{4}{|c|}{ Females $(n=91)$} \\
\hline & \multicolumn{2}{|c|}{ CTS $(n=15)$} & \multicolumn{2}{|c|}{ Control (n= 22) } & \multicolumn{2}{|c|}{ CTS (n = 33) } & \multicolumn{2}{|c|}{ Control $(n=58)$} \\
\hline \multirow[t]{3}{*}{ Age } & \multicolumn{2}{|c|}{$61.7 \pm 11.0^{*}$} & \multicolumn{2}{|c|}{$51.2 \pm 11.6$} & \multicolumn{2}{|c|}{$58.5 \pm 10.6^{*}$} & \multicolumn{2}{|c|}{$51.8 \pm 9.7$} \\
\hline & \multicolumn{8}{|c|}{ Laterality } \\
\hline & $\mathrm{n}$ & $\%$ & $\mathrm{n}$ & $\%$ & $\mathrm{n}$ & $\%$ & $n$ & $\%$ \\
\hline Right & 15 & 100.0 & 19 & 86.4 & 32 & 97.0 & 56 & 96.6 \\
\hline Left & 0 & - & 2 & 9.1 & 0 & - & 0 & - \\
\hline \multirow[t]{2}{*}{ Ambidextrous } & 0 & - & 1 & 4.5 & 1 & 3.0 & 2 & 3.4 \\
\hline & \multicolumn{8}{|c|}{ Place of residence } \\
\hline Urban & 12 & 80.0 & 18 & 81.8 & 20 & 60.6 & 42 & 72.4 \\
\hline \multirow[t]{2}{*}{ Rural } & 3 & 20.0 & 4 & 18.2 & 13 & 39.4 & 16 & 27.6 \\
\hline & \multicolumn{8}{|c|}{ Physical activity - sports } \\
\hline Yes & 10 & 66.7 & 16 & 72.7 & 22 & 66.7 & 40 & 69.0 \\
\hline No & 5 & 33.3 & 6 & 27.3 & 11 & 33.3 & 18 & 31.0 \\
\hline
\end{tabular}

${ }^{*} p<0.05$ indicates a significant difference between CTS group and the control group; CTS — carpal tunnel syndrome

ges I-V in females between patients with CTS and the control group, where mean value was higher in the CTS group (Table $3, p<0.001$ ). In females, means of circumferences of proximal fingers were significantly higher in the CTS group (Table 3, $p<0.001$ ). No significant differences were recorded in males (Table 3).
Total hand length, as well as the palm length without fingers was not statistically different between groups and genders (Table 4, $p>0.05$ ). Measurements of the width of the metacarpus, thickness of hand, the height of the thenar and the height of the thenar eminence did not shown statistical differences 
Table 3. Measured anthropometry parameters of fingers in analysed groups [mm]

\begin{tabular}{|c|c|c|c|c|c|c|c|c|}
\hline \multirow[t]{3}{*}{ Digit } & \multicolumn{4}{|c|}{ Males } & \multicolumn{4}{|c|}{ Females } \\
\hline & \multicolumn{2}{|c|}{ CTS (20 hands) } & \multicolumn{2}{|c|}{ Control (22 hands) } & \multicolumn{2}{|c|}{ CTS (51 hands) } & \multicolumn{2}{|c|}{ Control (58 hands) } \\
\hline & Mean & SD & Mean & SD & Mean & SD & Mean & SD \\
\hline & \multicolumn{8}{|c|}{ Digits length } \\
\hline I & 64.3 & 5.6 & 67.1 & 6.3 & 62.9 & 5.7 & 61.4 & 4.3 \\
\hline$\|$ & 92.4 & 8.2 & 95.0 & 5.5 & 87.8 & 5.8 & 87.2 & 4.7 \\
\hline III & 100.7 & 9.2 & 105.0 & 7.3 & 97.6 & 6.4 & 96.2 & 5.3 \\
\hline IV & 94.3 & 8.5 & 98.0 & 6.8 & 89.4 & 6.8 & 90.9 & 4.9 \\
\hline \multirow[t]{2}{*}{ V } & 76.7 & 8.2 & 79.4 & 6.7 & 72.4 & 6.8 & 72.3 & 5.7 \\
\hline & \multicolumn{8}{|c|}{ Functional length of digits } \\
\hline 1 & 63.1 & 7.0 & 63.2 & 5.0 & 59.0 & 5.3 & 59.3 & 3.8 \\
\hline$\|$ & 69.4 & 6.4 & 72.5 & 4.3 & 67.1 & 4.9 & 67.3 & 3.7 \\
\hline III & 75.8 & 6.4 & $79.2^{*}$ & 4.8 & 72.4 & 5.4 & 73.2 & 4.3 \\
\hline IV & 70.8 & 6.7 & 74.3 & 5.0 & 67.7 & 5.3 & 67.7 & 4.3 \\
\hline \multirow[t]{2}{*}{ V } & 58.4 & 5.9 & 60.4 & 4.7 & 54.1 & 5.8 & 54.8 & 3.9 \\
\hline & \multicolumn{8}{|c|}{ Width of the proximal phalanges — at the point of proximal interphalangeal joint } \\
\hline I & 24.6 & 2.5 & $26.2^{*}$ & 2.4 & $25.3^{*}$ & 2.7 & 24.0 & 2.4 \\
\hline II & 20.2 & 1.7 & 20.5 & 0.9 & $19.7^{*}$ & 1.6 & 18.3 & 1.3 \\
\hline III & 19.6 & 1.9 & 20.2 & 1.0 & $19.2^{*}$ & 1.5 & 17.8 & 1.2 \\
\hline IV & 18.7 & 1.4 & 19.1 & 0.9 & $17.9^{*}$ & 1.5 & 16.7 & 1.4 \\
\hline \multirow[t]{2}{*}{$\mathrm{V}$} & 16.6 & 1.4 & 16.9 & 1.1 & $16.1^{*}$ & 1.6 & 14.8 & 1.2 \\
\hline & \multicolumn{8}{|c|}{ Circumference of the proximal phalanges - at the point of the proximal digit base } \\
\hline I & 70.9 & 7.2 & 72.9 & 3.5 & $69.6^{*}$ & 6.2 & 63.4 & 4.7 \\
\hline$\|$ & 68.2 & 4.7 & 70.1 & 5.5 & $66.9^{*}$ & 6.5 & 63.5 & 4.9 \\
\hline III & 66.6 & 5.4 & 69.2 & 5.0 & $65.3^{*}$ & 6.3 & 61.7 & 5.3 \\
\hline IV & 62.3 & 4.6 & 64.8 & 4.6 & $60.6^{*}$ & 6.4 & 58.0 & 5.5 \\
\hline V & 55.8 & 5.8 & 58.2 & 5.0 & $55.0^{*}$ & 5.9 & 52.6 & 4.9 \\
\hline
\end{tabular}

${ }^{*} p<0.05$ indicates a significant difference between CTS group and the control group; I-V — number of finger; CTS — carpal tunnel syndrome, SD — standard deviation

Table 4. Measured anthropometry parameters of the hand in analysed groups [mm]

\begin{tabular}{|c|c|c|c|c|c|c|c|c|}
\hline & \multicolumn{4}{|c|}{ Males } & \multicolumn{4}{|c|}{ Females } \\
\hline & \multicolumn{2}{|c|}{ CTS (20 hands) } & \multicolumn{2}{|c|}{ Control (22 hands) } & \multicolumn{2}{|c|}{ CTS (51 hands) } & \multicolumn{2}{|c|}{ Control (58 hands) } \\
\hline & Mean & SD & Mean & SD & Mean & SD & Mean & SD \\
\hline Wrist width & 57.8 & 4.2 & $63.9^{*}$ & 3.2 & 53.8 & 2.4 & $56.8^{*}$ & 3.6 \\
\hline Wrist circumference & 184.9 & 12.0 & 180.4 & 11.6 & $166.7^{*}$ & 10.5 & 161.3 & 11.2 \\
\hline Wrist depth & 47.1 & 3.8 & 43.5 & 3.9 & $39.7^{*}$ & 2.8 & 37.5 & 2.7 \\
\hline Hand length & 180.9 & 13.5 & 186.0 & 12.0 & 172.8 & 11.6 & 172.5 & 9.0 \\
\hline Hand width in the metacarpus & 87.7 & 5.3 & 87.0 & 4.0 & 79.5 & 3.9 & 86.2 & 3.9 \\
\hline Palm length without fingers & 114.7 & 3.8 & 113.5 & 7.5 & 105.0 & 4.3 & 104.2 & 5.4 \\
\hline Palm thickness & 32.1 & 4.9 & 31.7 & 4.8 & 29.4 & 4.2 & 29.8 & 3.7 \\
\hline Height of the hypothenar & 33.9 & 5.1 & 32.2 & 6.3 & 30.6 & 4.8 & 31.7 & 4.1 \\
\hline Height of the thenar & 42.0 & 6.8 & 42.7 & 6.1 & 37.8 & 6.1 & 38.7 & 5.5 \\
\hline Palm circumference & 211.8 & 14.6 & 214.1 & 11.7 & 191.4 & 10.2 & 190.9 & 10.5 \\
\hline Hand circumference & 214.0 & 16.8 & 250.2 & 14.1 & 226.8 & 10.7 & 224.9 & 11.4 \\
\hline
\end{tabular}

${ }^{*} p<0.05$ indicates a significant difference between CTS group and the control group; CTS — carpal tunnel syndrome; SD — standard deviation 
in analysed groups and genders $(p>0.05)$. Statistical analysis has shown that narrower wrists occur in patients with CTS when compared to the control group, both in males and females $(p=0.02$ and $p=0.004$, respectively). Mean value of the height (depth) of the wrist was significantly higher in the female CTS group $(p=0.03)$, with a similar trend in the male CTS group $(p=0.08)$.

Measurement of the circumference of the wrist has shown that females with CTS have a higher mean value than the control group (Table $4, p<0.001$ ), but we could not observe the same finding in males $(p>0.05)$. Mean values of hand circumference measured in the finger area were higher in CTS group than in the control group of women (Table 4, $p=0.007$ ). However, the circumference of the palm and hand (with the thumb adducted) were similar in both groups (Table 4, both $p>0.05$ ). No differences in mentioned parameters were found in males between the CTS group and control group.

We have noted that the mean value of the body height of the females with CTS $(158.9 \pm 4.6 \mathrm{~cm})$ was significantly lower than in the control group (162 \pm $\pm 5.5 \mathrm{~cm} ; p=0.025$ ). We could not observe the same finding in males. There were no statistically significant differences in length of the arm, forearm and the total length of the upper limb between analysed groups and genders (Table 5, $\mathrm{p}>0.05$ ).

Correlation coincidences were analysed between the width of each proximal phalange, the width of the hand in metacarpal area and body weight (Table 6). In the female control group there were significant correlations between body weight and each finger width (except thumb) as well as metacarpal width $(p<0.001 ; r=0.35-0.57)$. In the CTS group such correlation was observed for both sexes, but for the metacarpal width only $(p<0.001 ; r=0.56-0.71$; Table 6). Correlation coincidences were also analysed between circumferences within the hand, palm and body weight (Table 6) and significant correlations with the individual fingers circumferences occurred only in the female control group $(p<0.001, r=0.46-0.63)$. Furthermore, all remaining measured circumferences were correlated with body weight in both groups and genders (Table 6, $\mathrm{p}<0.05$ ).

Calculated indexes are presented in the Table 7. The wrist index was calculated in every group and the value was statistically higher in both males and females from CTS group compared with the control group ( $p=0.01$ and $p<0.001$, respectively). Com- puted shape and digit indexes, as well as hand length/ height ratios and hand length/upper limb ratios have not shown any significant differences between the control and CTS groups in either gender $(p>0.05)$.

The BMI of females with CTS was significantly higher than in females form the control group (29.8 \pm \pm 5.0 vs. $\left.25.7 \pm 5.3 \mathrm{~kg} / \mathrm{m}^{2} ; \mathrm{p}<0.001\right)$. The males' BMI was similar in both groups ( $27.9 \pm 4.0$ vs. $25.7 \pm$ $\left.\pm 2.6 \mathrm{~kg} / \mathrm{m}^{2} ; \mathrm{p}>0.05\right)$. Based on the World Health Organisation classification of BMI, we have observed that almost $90.0 \%$ of females with diagnosed CTS have an elevated BMI, wherein $54.5 \%$ of females were considered overweight and $33.3 \%$ considered obese. In the control group, overweight and obesity status was observed in $31.0 \%$ and $17.2 \%$ of cases, respectively. In the male CTS group, $46.7 \%$ and $26.7 \%$ of patients were considered overweight and obese, respectively. It is important to note, that $72.7 \%$ of the males in the control group were also considered overweight. No statistical significance differences were recorded in the percentage of overweight and obese individuals between CTS and control group $(p>0.05)$.

\section{DISCUSSION}

The aim of this study was to evaluate the hypothesis that the CTS is related to hand morphometry. Factors not directly related to anthropometric measurements was also considered in this study and included: age, BMI, place of residence and daily physical activity to find potential links to CTS occurrence.

Previous authors have stated that CTS is more common in people above 40 years old, and that risk increases with age $[18,31,34]$. This is why our control group consisted mainly of mature individuals (Table 2) to best match patients in the CTS group. Other factors in addition to age are equally important. Physical factors such as repeatable pressure, systematic bending or torsion of the hand with the wrist during work activity, using vibrating tools, some everyday activities, as well as hand trauma can lead to CTS $[4,13,22,23,33]$. In addition, individual factors such as gender, pregnancy, endocrine disorders, diabetes or connective tissue disorders could indirectly and directly influence CTS manifestation [17, 26]. Two other medical factors predisposing to this condition, such as rheumatoid arthritis and kidney failure can be also included in that list [5].

As aforementioned, it is well known that CTS is more frequent in women [3]. In our patient study 
Table 5. Measured anthropometry parameters of the body in analysed groups

\begin{tabular}{|c|c|c|c|c|c|c|c|c|}
\hline & \multicolumn{4}{|c|}{ Males } & \multicolumn{4}{|c|}{ Females } \\
\hline & \multicolumn{2}{|c|}{ CTS (20 hands) } & \multicolumn{2}{|c|}{ Control (22 hands) } & \multicolumn{2}{|c|}{ CTS (51 hands) } & \multicolumn{2}{|c|}{ Control (58 hands) } \\
\hline & Mean & SD & Mean & SD & Mean & SD & Mean & SD \\
\hline Body height [cm] & 169.2 & 4.8 & 174.4 & 9.4 & 158.6 & 4.6 & 161.7 & 5.5 \\
\hline Arm length [cm] & 34.1 & 2.9 & 34.4 & 3.8 & 31.7 & 2.0 & 30.8 & 1.9 \\
\hline Forearm length $[\mathrm{cm}]$ & 24.5 & 2.7 & 22.8 & 4.1 & 20.7 & 2.2 & 21.2 & 1.9 \\
\hline
\end{tabular}

CTS — carpal tunnel syndrome; SD — standard deviation

Table 6. Association between proximal phalanges and hand circumferences and body weight, as well as, width of proximal phalanges, hand and body weight

\begin{tabular}{|c|c|c|c|c|c|c|c|c|}
\hline & \multicolumn{4}{|c|}{ Males } & \multicolumn{4}{|c|}{ Females } \\
\hline & \multicolumn{2}{|c|}{ CTS (20 hands) } & \multicolumn{2}{|c|}{ Control (22 hands) } & \multicolumn{2}{|c|}{ CTS (51 hands) } & \multicolumn{2}{|c|}{ Control (58 hands) } \\
\hline & $\mathbf{r}$ & $\mathbf{p}$ & $\mathbf{r}$ & $\mathbf{p}$ & $\mathbf{r}$ & $\mathbf{p}$ & $\mathbf{r}$ & $\mathbf{p}$ \\
\hline & \multicolumn{8}{|c|}{ Association between proximal phalanges width and hand width in the metacarpus and body weight } \\
\hline I & 0.15 & NS & 0.30 & NS & 0.06 & NS & 0.16 & NS \\
\hline$\|$ & -0.01 & NS & -0.02 & NS & 0.02 & NS & 0.57 & $<0.001$ \\
\hline III & 0.29 & NS & -0.11 & NS & 0.05 & NS & 0.35 & 0.012 \\
\hline IV & 0.10 & NS & 0.05 & NS & -0.02 & NS & 0.56 & $<0.001$ \\
\hline V & 0.33 & NS & -0.03 & NS & 0.10 & NS & 0.51 & $<0.001$ \\
\hline \multirow[t]{2}{*}{ Hand width in the metacarpus } & 0.64 & 0.002 & 0.71 & $<0.001$ & 0.56 & $<0.001$ & 0.57 & $<0.001$ \\
\hline & \multicolumn{8}{|c|}{ Association between circumferences and body weight } \\
\hline I & 0.19 & NS & 0.33 & NS & 0.03 & NS & 0.62 & $<0.001$ \\
\hline$\|$ & -0.07 & NS & 0.37 & NS & 0.12 & NS & 0.63 & $<0.001$ \\
\hline III & 0.27 & NS & 0.20 & NS & 0.15 & NS & 0.46 & $<0.001$ \\
\hline IV & 0.05 & NS & 0.35 & NS & -0.05 & NS & 0.59 & $<0.001$ \\
\hline V & 0.10 & NS & 0.32 & NS & 0.01 & NS & 0.49 & $<0.001$ \\
\hline Palm circumference & 0.53 & 0.014 & 0.75 & $<0.001$ & 0.40 & 0.002 & 0.59 & $<0.001$ \\
\hline Hand circumference & 0.74 & $<0.001$ & 0.79 & $<0.001$ & 0.49 & $<0.001$ & 0.63 & $<0.001$ \\
\hline Circumference through fingers & 0.73 & $<0.001$ & 0.47 & 0.033 & 0.42 & $<0.001$ & 0.56 & $<0.001$ \\
\hline Wrist circumference & 0.70 & $<0.001$ & 0.74 & $<0.001$ & 0.61 & $<0.001$ & 0.80 & $<0.001$ \\
\hline
\end{tabular}

I-V — proximal phalanges; NS — non-significant; CTS — carpal tunnel syndrome

Table 7. Calculated hand indexes of analysed groups

\begin{tabular}{|c|c|c|c|c|c|c|c|c|}
\hline & \multicolumn{4}{|c|}{ Males } & \multicolumn{4}{|c|}{ Females } \\
\hline & \multicolumn{2}{|c|}{ CTS (20 hands) } & \multicolumn{2}{|c|}{ Control (22 hands) } & \multicolumn{2}{|c|}{ CTS (51 hands) } & \multicolumn{2}{|c|}{ Control (58 hands) } \\
\hline & Mean & SD & Mean & SD & Mean & SD & Mean & SD \\
\hline Wrist index & $0.80^{*}$ & 0.06 & 0.68 & 0.07 & $0.74^{*}$ & 0.03 & 0.66 & 0.05 \\
\hline Shape index & 76.5 & 4.5 & 77.0 & 4.7 & 75.8 & 4.2 & 75.1 & 3.2 \\
\hline Digit index & 55.7 & 3.3 & 56.5 & 3.6 & 56.5 & 2.6 & 55.9 & 2.9 \\
\hline Hand length/height ratio & 10.6 & 1.1 & 10.7 & 0.5 & 10.9 & 0.8 & 10.7 & 0.5 \\
\hline Hand length/upper limb length ratio & 23.6 & 2.6 & 24.4 & 1.5 & 24.9 & 1.5 & 24.8 & 1.2 \\
\hline Body mass index $\left[\mathrm{kg} / \mathrm{m}^{2}\right]$ & 27.9 & 4.0 & 25.7 & 2.6 & $29.8^{*}$ & 5.0 & 25.7 & 5.3 \\
\hline
\end{tabular}

${ }^{*} \mathrm{p}<0.05$ indicates a significant difference between CTS group and the control group; CTS — carpal tunnel syndrome; SD — standard deviation

Shape index - hand width in the metacarpus $[\mathrm{mm}] \times 100 /$ hand length $[\mathrm{mm}]$

Digit index — digit length $[\mathrm{mm}] \times 100 /$ hand length $[\mathrm{mm}]$

Wrist index — wrist depth [mm] / wrist width [mm]) 
group, females were far more prevalent than males, accounting for $70 \%$ of all patients. This prevalence may be related to an increased predisposition of females to being overweight, especially in the peri- and postmenopausal periods [21]. It can be also related to hormone level fluctuations [16]. Oestrogen receptors are located in the central and peripheral nervous systems and one of its relevant actions is neuron proliferation and regeneration $[12,28]$. At the perimenopausal age, oestrogen levels are reduced and can influence the medial nerve and other structures located in the carpal tunnel [16]. With respect to body height, females with CTS were significantly shorter than control subjects. This result is dependent on the selection of the control group. However, Chiotis et al. [5] reported similar findings. They examined only women and revealed that females with CTS had a smaller average body height as well as a higher BMI than the control group. Moreover, Mondelli et al. [25] have shown that in clinical practice, the cut-off values for many anthropometric measurements have limited value as tools for the diagnosis of CTS.

We haven't noticed any significant differences between the CTS patients and control individuals in the lengths and functional lengths of digits as well as total hand length and palm length without fingers. Moreover, no relation was found between CTS occurrence in both genders and height measurements of the hand. Research conducted by Hlebs et al. [10] showed that people with CTS have shorter third digits than healthy volunteers, but our study did not replicate the same dependence.

A completely different situation is observed with width measurements and circumferences of the hand. It has been shown that the widths of the proximal phalanges in females are significantly different between CTS patients and healthy volunteers. Higher mean values of width measurement of the proximal phalanges were observed in females with CTS. On the other hand, no such differences between CTS and healthy subjects were recorded in males. It may be due to the fact that width measurements are dependent on body weight. Females at the perimenopausal age tend to have increased weight and BMI which may consequently favour the manifestation of CTS $[12,28]$. In our research, females with CTS have significantly higher BMI values, with almost $90 \%$ having a BMI above $25.0 \mathrm{~kg} / \mathrm{m}^{2}$. A similar tendency was found in other studies, wherein people with CTS had elevated BMI values. Hence, it is reasonable to say that
CTS is related to body fat content $[4,7,11]$. Increased fat mass within the carpal tunnel and hydrostatic pressure in obese people can be an indirect factor in elevated morbidity in CTS [34]. Other indexes did not demonstrate any significant difference between patients with CTS and volunteers.

Interestingly, our study shows that in CTS patients, thenar eminence dimensions were similar to the values obtained in the control group. Previous studies indicated that severe CTS is often accompanied by thenar eminence muscles atrophy caused by compression of the motor branch of the median nerve [6]. In the current study, patients were not categorised by the severity of symptoms as it was presented in previous publications [4]. It may be the reason why the averaged measurements for all subjects of our study did not show muscle atrophy.

Higher values of the wrist index are characteristic of people with CTS, concerning both men and women. There is no evident explanation about link between wrist structure and its predisposition to CTS occurrence in current literature $[4,9]$. Some authors have shown dependence between the wrist index and CTS (odds ratio: 1.35, $p<0.001$ ) $[4,14,30]$. Kouyoumdjian et al. $[19,20]$ indicates that higher values of the wrist ratio is an increased risk factor of CTS occurrence. It is suggested that values of the wrist ratio can be related with changes in the canal, such as static and dynamic changes between the wrist ligaments or nerves. It is believed that a stronger association with CTS is observable for the wrist ratio (depth to width ratio) than for direct dimensions such as circumference or width, which suggests that the shape of wrist is more significant than its dimensions [24]. Moreover, some authors suggest that CTS emergence is connected with nerve conduction velocity along the medial nerve, which in turn is connected with age, body height and BMI [8].

Kamolz et al. [15] implement wrist classification according to its shape with two main types: rectangular and square. For the former, the mean value of the wrist ratio is 0.65 and for the latter, it is above 0.70 . Patients with wide wrists with a square shape may have slower nerve impulse speed along the sensory and motor fibres in the canal [5]. The critical value of the wrist index which may lead to a decrease in conduction velocity is 0.7 (square shape). Our research demonstrates values of 0.8 and 0.74 , respectively for males and females of our CTS group, which indicates a mainly square shape of the wrist. 
Moreover, such a shape may directly translate into the ligaments within the carpal tunnel; they are thicker as the channel becomes narrower. This may lead to the increased pressure on the blood vessels and the median nerve $[10,29]$.

This study is not without limitations and the main one could be the small number of male subjects included in both study and control group. Future studies are needed to determine whether wrist shape is correlated just with the soft tissue or with the geometry of the bones as well. The latter requires anthropometric study based on wrist X-ray scanning.

\section{CONCLUSIONS}

There are significant differences in morphometrical features of the upper limbs between CTS patients and healthy individuals. Our study results have, in many aspects, confirmed our clinical observations that hands of patients with CTS are more massive and with 'plumb' fingers. Square shape of the wrist was observed in CTS group, which is considered to be the most significant risk factor in CTS development. In females we have noted higher values of the widths and circumferences of the proximal phalanges. The length dimensions of the upper limb did not appear to be different in CTS patients. Furthermore, higher BMI values were confirmed to be predisposing factors in CTS occurrence.

\section{REFERENCES}

1. Alford JW, Weiss APC, Akelman E. The familial incidence of carpal tunnel syndrome in patients with unilateral and bilateral disease. Am J Orthop (Belle Mead NJ). 2004; 33(8): 397-400, indexed in Pubmed: 15379235.

2. Becker J, Nora DB, Gomes I, et al. An evaluation of gender, obesity, age and diabetes mellitus as risk factors for carpal tunnel syndrome. Clin Neurophysiol. 2002; 113(9): 1429-1434, indexed in Pubmed: 12169324.

3. Bongers FJM, Schellevis FG, van den Bosch WJ, et al. Carpal tunnel syndrome in general practice (1987 and 2001): incidence and the role of occupational and non-occupational factors. Br J Gen Pract. 2007; 57(534): 36-39, indexed in Pubmed: 17244422.

4. Boz C, Ozmenoglu M, Altunayoglu V, et al. Individual risk factors for carpal tunnel syndrome: an evaluation of body mass index, wrist index and hand anthropometric measurements. Clin Neurol Neurosurg. 2004; 106(4): 294-299, doi: 10.1016/j.clineuro.2004.01.002, indexed in Pubmed: 15297003.

5. Chiotis K, Dimisianos N, Rigopoulou A, et al. Role of anthropometric characteristics in idiopathic carpal tunnel syndrome. Arch Phys Med Rehabil. 2013; 94(4): 737-744, doi: 10.1016/j.apmr.2012.11.017, indexed in Pubmed: 23178273.

6. Fernandes $\mathrm{CH}$, Meirelles LM, Raduan Neto J, et al. Carpal tunnel syndrome with thenar atrophy: evaluation of the pinch and grip strength in patients undergoing surgical treatment. Hand (N Y). 2013; 8(1): 60-63, doi: 10.1007/s11552-012-9471-8, indexed in Pubmed: 24426894.

7. Frankenfield DC, Rowe WA, Cooney RN, et al. Limits of body mass index to detect obesity and predict body composition. Nutrition. 2001; 17(1): 26-30, indexed in Pubmed: 11165884.

8. Fujimaki Y, Kuwabara S, Sato $Y$, et al. The effects of age, gender, and body mass index on amplitude of sensory nerve action potentials: multivariate analyses. Clin Neurophysiol. 2009; 120(9): 1683-1686, doi: 10.1016/j. clinph.2009.06.025, indexed in Pubmed: 19640782.

9. Gordon C, Johnson EW, Gatens PF, et al. Wrist ratio correlation with carpal tunnel syndrome in industry. Am J Phys Med Rehabil. 1988; 67(6): 270-272, indexed in Pubmed: 3196452.

10. Hlebs S, Majhenic K, Vidmar G. Body mass index and anthropometric characteristics of the hand as risk factors for carpal tunnel syndrome. Coll Antropol. 2014; 38(1): 219-226, indexed in Pubmed: 24851621.

11. Hortobágyi T, Israel RG, O'Brien KF. Sensitivity and specificity of the Quetelet index to assess obesity in men and women. Eur J Clin Nutr. 1994; 48(5): 369-375, indexed in Pubmed: 8055853.

12. Islamov RR, Hendricks WA, Katwa LC, et al. Effect of 17 beta-estradiol on gene expression in lumbar spinal cord following sciatic nerve crush injury in ovariectomized mice. Brain Res. 2003; 966(1): 65-75, indexed in Pubmed: 12646309.

13. Jenkins PJ, Srikantharajah D, Duckworth $A D$, et al. Carpal tunnel syndrome: the association with occupation at a population level. J Hand Surg Eur Vol. 2013; 38(1): 67-72, doi: 10.1177/1753193412455790, indexed in Pubmed: 22832982

14. Johnson EW, Gatens T, Poindexter D, et al. Wrist dimensions: correlation with median sensory latencies. Arch Phys Med Rehabil. 1983; 64(11): 556-557, indexed in Pubmed: 6639317.

15. Kamolz LP, Beck H, Haslik W, et al. Carpal tunnel syndrome: a question of hand and wrist configurations? J Hand Surg Br. 2004; 29(4): 321-324, doi: 10.1016/j.jhsb.2003.09.010, indexed in Pubmed: 15234493.

16. Kaplan Y, Kurt SG, Karaer H. Carpal tunnel syndrome in postmenopausal women. J Neurol Sci. 2008; 270(1-2): 77-81, doi: 10.1016/j. jns.2008.02.003, indexed in Pubmed: 18325536.

17. Karpitskaya Y, Novak CB, Mackinnon SE. Prevalence of smoking, obesity, diabetes mellitus, and thyroid disease in patients with carpal tunnel syndrome. Ann Plast Surg. 2002; 48(3): 269-273, indexed in Pubmed: 11862031.

18. Komurcu HF, Kilic S, Anlar O. Relationship of age, body mass index, wrist and waist circumferences to carpal tunnel syndrome severity. Neurol Med Chir (Tokyo). 2014; 54(5): 395-400, indexed in Pubmed: 24257492.

19. Kouyoumdjian JA, Morita MP, Rocha PR, et al. Wrist and palm indexes in carpal tunnel syndrome. Arq Neuropsiquiatr. 2000; 58(3A): 625-629, indexed in Pubmed: 10973101.

20. Kouyoumdjian JA, Zanetta DMT, Morita MPA. Evaluation of age, body mass index, and wrist index as risk factors for carpal tunnel syndrome severity. Muscle Nerve. 2002; 25(1): 93-97, indexed in Pubmed: 11754190.

21. Lam N, Thurston A. Association of obesity, gender, age and occupation with carpal tunnel syndrome. Aust N Z J Surg. 1998; 68(3): 190-193, indexed in Pubmed: 9563447.

22. Loslever P, Ranaivosoa A. Biomechanical and epidemiological investigation of carpal tunnel syndrome at workplaces with high risk factors. Ergonomics. 1993; 36(5): 537-555, doi: 10.1080/00140139308967911, indexed in Pubmed: 8500474.

23. McDiarmid M, Oliver M, Ruser J, et al. Male and female rate differences in carpal tunnel syndrome injuries: personal attributes or job tasks? Environ Res. 2000; 83(1): 23-32, doi: 10.1006/enrs.2000.4042, indexed in Pubmed: 10845778

24. Mogk JPM, Keir PJ. Wrist and carpal tunnel size and shape measurements: effects of posture. Clin Biomech (Bristol, Avon). 2008; 23(9): 1112-1120, doi: 10.1016/j.clinbiomech.2008.05.009, indexed in Pubmed: 18635295

25. Mondelli M, Curti S, Farioli A, et al. Anthropometric measurements as a screening test for carpal tunnel syndrome: receiver operating characteristic curves and accuracy. Arthritis Care Res (Hoboken). 2015; 67(5): 691-700, doi: 10.1002/acr.22465, indexed in Pubmed: 25187375.

26. Nathan PA, Keniston RC. Carpal tunnel syndrome and its relation to general physical condition. Hand Clin. 1993; 9(2): 253-261, indexed in Pubmed: 8509465.

27. Nathan PA, Meadows KD, Istvan JA. Predictors of carpal tunnel syndrome: an 11-year study of industrial workers. J Hand Surg Am. 2002; 27(4): 644-651, indexed in Pubmed: 12132090.

28. Papka RE, Hafemeister J, Puder BA, et al. Estrogen receptor-alpha and neural circuits to the spinal cord during pregnancy. J Neurosci Res. 2002; 70(6): 808-816, doi: 10.1002/jnr.10421, indexed in Pubmed: 12444603.

29. Radecki P. A gender specific wrist ratio and the likelihood of a median nerve abnormality at the carpal tunnel. Am J Phys Med Rehabil. 1994; 73(3): 157-162, indexed in Pubmed: 8198771.

30. Sharifi-Mollayousefi A, Yazdchi-Marandi M, Ayramlou H, et al. Assessment of body mass index and hand anthropometric measurements as independent risk factors for carpal tunnel syndrome. Folia Morphol. 2008; 67(1): 36-42, indexed in Pubmed: 18335412.

31. Stevens JC, Sun S, Beard CM, et al. Carpal tunnel syndrome in Rochester, Minnesota, 1961 to 1980 . Neurology. 1988; 38(1): 134-138, indexed in Pubmed: 3336444.

32. Tseng CH, Liao CC, Kuo CM, et al. Medical and non-medical correlates of carpal tunnel syndrome in a Taiwan cohort of one million. Eur J Neurol. 2012; 19(1): 91-97, doi: 10.1111/j.1468-1331.2011.03440.x, indexed in Pubmed: 21631646

33. Werner R, Armstrong TJ, Bir C, et al. Intracarpal canal pressures: the role of finger, hand, wrist and forearm position. Clin Biomech (Bristol, Avon). 1997: 12(1): 44-51, indexed in Pubmed: 11415671.

34. Werner RA, Albers JW, Franzblau A, et al. The relationship between body mass index and the diagnosis of carpal tunnel syndrome. Muscle Nerve. 1994; 17(6): 632-636, doi: 10.1002/mus.880170610, indexed in Pubmed: 8196706.

35. Zyluk A, Dabal L, Szlosser Z. [Association of anthropometric factors and predisposition to carpal tunnel syndrome]. Chir Narzadow Ruchu Ortop Pol. 2011; 76(4): 193-196, indexed in Pubmed: 22235640. 